\title{
Fragmentos de historia popular / I
}

\section{Eva Salgado Andrade}

a creciente penetración cultural que inunda los campos de nuestra propia identidad, hace imperativo preservar, defender y consolidar las múltiples manifestaciones que integran nuestra cultura. Para tal efecto, una de las barreras que se han erigido está representada por el concepto de lo popular. Muchas veces llevada y traída, esta palabra puede en ocasiones referirse a algo completamente distinto de la finalidad original: no es raro que con la simple enunciación del término popular, se pretenda - sin mayor requisito- convertir cualquier manifestación cultural en algo surgido del pueblo y para el pueblo. Sin embargo, más allá de este uso superficial, el rescate de lo auténticamente popular es una labor imprescindible, a la cual es menester dedicar cuanto esfuerzo sea necesario. Afortunadamente, esta tarea ya se realiza en numerosas instituciones; pero aún quedan zonas inexploradas.

Lo popular abarca tantos campos como manifestaciones culturales existen; asi, se habla de educación popular, arte popular, comunicación popular, y, ¿por qué no?, historia popular. Este último concepto engloba nuestro pasado común, construido a partir de los cimientos del pueblo, de los artífices anónimos del cambio. La idea de lo popular, aplicada a la historia, permitirá rescatar herencias valiosas que aún perduran en el presente.

Toda sociedad está necesariamente condicionada por un cúmulo de experiencias colectivas; el pasado no se agota, sino que se encadena al presente. No son tiempos separados; las lineas cronológicas se desvanecen y lo que hoy es presente mañana será pasado y lo que ayer fue presente hoy es pasado.

El rescate de la historia popular permitirá conocer no sólo los grandes hechos que todos registran, sino también pequeños fenómenos ignorados por la mayoria de los autores. Todos nosotros sentimos, actuamos, observamos, criticamos; no nos gustaría que el día de mañana no quede el menor rastro de nuestra incursión por este mundo. Se desprende asi otro punto a favor de la historia popular, pues permite escuchar a algunos de los anónimos de la historia, así como conocer sus pequeñas, a la vez que grandes, aportaciones.

Con la historia popular se pone al alcance de muchos las lecciones del pasado. "En la experiencia de la historia los pueblos se liberan de sus ilusiones, llegan a comprender la necesidad y el significado de la lucha política."' En la medida en que tales experiencias provienen de gente común y corriente, es posible lograr un acercamiento entre los sectores aparentemente marginados de la acción y el conocimiento histórico.

Una labor tan trascendental como la reconstrucción de la historia no puede asumirse a la ligera. Los científicos sociales deben reconocer la gran responsabilidad que pesa sobre sus espaldas y deben tener muy presente que este concepto, dada su amplia esencia, se presta también para hacer del pasado un falso paradigma de triunfos y epopeyas. "La

' Boris Moguilnitski, "Importancia de la experiencia histórica", en Metodología de la investigación histórica. Ediciones Quinto Sol, México, s/f, p. 202. 
concepción del mundo, los ideales político-sociales, el sistema de valores espirituales, están determinados por la pertenencia del historiador a una clase, partido, nación, Estado (...) que engendran determinados criterios de valorización por los que él se guia (consciente o inconscientemente) en la investigación del pasado de la humanidad."2

Además de servir para explicar cientificamente los procesos del pasado, para comprender mejor el presente y el futuro, la historia funciona no sólo en representaciones colectivas referidas al presente, sino remontadas hacia el pasado. Sirve para inspirar el contenido de los mensajes masivos con los cuales se da a los individuos la mejor visión de lo que su país fue, es y será. "Parecería que en cada tramo prolongado de historia - ya se trate de un mundo cultural o de un pueblo- encontramos un mito y una utopia que dominan, y que la política se ha movido invocando ese mito y reclamando esa utopía." 3

Las soluciones para desmitificar ese pasado histórico lleno de falsas excelsitudes no se agotan en el análisis exhaustivo de los procesos económicos y sociales; debe también recurrirse, cuando ello sea posible, a las voces de los actores, de los que lo vivieron; aquéllos que - sin figurar siquiera en modestos periódicos locales - tuvieron alguna participación y desean opinar sobre lo que vieron y vivieron, aunque fuera en un segundo o tercer plano. "A la versión oficial del pasado, conforme con los intereses del poder y, por lo tanto, mutilada, censurada, deformada, las masás oponen una imagen más sólida, una imagen conforme con sus aspiraciones y que refleja la riqueza real de su pasado."4

Al escuchar nuevas voces no solamente se obtienen fuentes alternativas, sino que se genera mayor interés de los individuos hacia la historia, pues existe en ellos el aliciente de que se les toma en cuenta y que ese algo tan alejado (como se nos figura a veces la historia) se nutre de múltiples viviencias que todos aportamos. "Están sugiendo nuevas formas de resistencia y reapropiación de lo popular frente al embate de la ideología dominante: nuevas identidades producto de lo propio que forma parte de su memoria colectiva." 5

La importancia de la visión popular está más que justificada, pues: "No son las elites, es el cuerpo multi-membre del pueblo el que ha sostenido a la historia, la ha orientado en direcciones nuevas en puntos críticos de inflexión y ha elevado paso a paso a la humanidad."6 $\mathrm{La}$ historia popular se convierte en una valiosa herramienta de construcción de la identidad, de compartir unos con otros las experiencias y la memoria colectiva. "Si la historia es realmente una referencia activa y colectiva al pasado, la reflexión sobre la historia no puede ser sino activa y colectiva también; las contribuciones individuales sólo cuentan en la medida en que se insertan en esta relación activa y colectiva, para mejor formularla, para darle más fuerza."7

2 P. F. Laptin, "Sobre el papel de la hipótesis en las investigaciones históricas", en $M e-$ todología de la investigación histórica, op. cit., p. 100.

"José María Bulnes, "Determinaciones retóricas del discurso político latinoamericano", en El discurso político, Nueva Imagen/UNAM, México, 1978, p. 304.

4 Jean Chesneaux, ¿Hacemos tabla rasa del pasado?, Siglo XXI Editores, 5a. ed., México, 1983 , p. 40.

5 Cecilia Blondet, "Memoria colectiva y resistencia popular", en Materiales para la comunicación popular, núm. 2, enero de 1984, Centro de Estudios sobre Cultura Transnacional, Lima, 1984, p. 5.

- George Novak, Para comprender la historia. Editorial Fontamara, México, 1984, p. 32 .

\footnotetext{
7 Jean Chesneaux, op. cit., p. 17.
} 
Por otra parte, el concepto de historia popular implica una doble vertiente: de un lado, rescatar todo lo que sea posible sobre lo popular en la historia, como se ha expuesto en líneas anteriores; de otro, este concepto de popular no se refiere sólo al rescate de fuentes que enriquezcan los archivos, sino que debe procurarse que esas manifestaciones se difundan. Lo popular, lejos de ser sólo un proceso de extracción de material, debe ser también una manera de comunicar, de atraer el interés de la gente para que cobre conciencia del significado de la historia; si se escuchan unos a otros, si comparten sus experiencias, sentirán la historia como algo más propio

Lo popular se encuentra en aquellas manifestaciones que hoy se conocen como de cultura popular y que mañana, al fundirse paulatinamente con el pasado, serán historia popular: tradiciones, mitos, leyendas, festividades, héroes de la comunidad, etcétera. También lo popular existe como una masa in forme en el interior decada persona, llámense recuerdos almancenados o experiencias particulares. De alguna manera es factible rescatar, aunque sea en una minima proporción, estas experiencias para ofrecerlas a otros. Para ello sería conveniente proceder de acuerdo con una o varias metodologías que hagan posible la obtención de opiniones espontáneas, lo menos contaminadas que sea posible, y emplearlas para el análisis de los procesos históricos, junto con fuentes bibliohemográficas, documentales, etcétera.

La historia oral ofrece una de estas metodologías de rescate de fuentes históricas alternativas, y consiste en "un método auxiliar de la investigación histórica, cuyo propósito esencial es la creación y el enriquecimiento de fondos testimoniales, grabados en cintas magnetofónicas, con la información de primera mano que pueden proporcionar los testigos presenciales de los diferentes procesos históricos. En su función de entrevistador, el historiador inquiere a la 'historia viva': el entrevistado." 8

Por fortuna para cuantos se interesen en el tema, en nuestro país ya se han emprendido diversos proyectos de historia oral. Pionero sin duda, el Archivo de la Palabra - desarrollado primero en el Instituto Nacional de Antropología e Historia y ahora también en el Instituto de Investigaciones Dr. José Maria Luis Mora- ha logrado obtener, preservar y difundir centenares de valiosos testimonios que recrean episodios de nuestra historia contemporánea.

La serie de "Fragmentos de Historia Popular" que se inicia en estas páginas tiene como fin básico la difusión de una parte, aunque muy pequeña, de estos testimonios. Pretende convertirse en escaparate de diversas experiencias, impresiones y opiniones acerca de pasajes relevantes de nuestra historia pero también, y principalmente, de pequeños fenómenos que de alguna manera contribuyen a integrar nuestra historia. Procesos o fenómenos como la vida cotidiana a la par de los grandes cambios sociales, la participación de los niños o los adolescentes en los hechos históricos, recuentos de experiencias locales que la historia ha olvidado poco a poco, héroes que sólo lo son para un reducido sector, participación específica de algunos núcleos, por ejemplo mujeres, estudiantes, obreros, campesinos.

Pretendemos reunir fragmentos que, a manera de breves antologías, permitan que nos conozcamos más, que sepamos cómo procedieron

"Eugenia Meyer, "Prólogo"a Palabras del exilio I. Contribución a la historia de los refugiados españoles en México, INAH/Libreria Madero, México, 1980, p. 13. 
algunos de nuestros congéneres en determinados momentos de la historia que, a fin de cuentas, nos es común a todos. La lectura de estas líneas nos hará pensar, entre otras cosas, que algún día nosotros también seremos parte de un pasado encadenado al presente. "Es bueno considerar, de vez en cuando, el presente como si fuera ya pasado, y examinar cuáles de sus elementos enriquecerán el depósito de posesiones permanentes del universo, cuáles vivirán y darán vida cuando nosotros y toda nuestra generación hayamos desaparecido."9

Para ser consecuentes con esta presentación, hemos elegido como primera muestra una breve antología de opiniones sobre historia, concretamente referidas al proceso de la Revolución mexicana en la cual todos los informantes participaron o, como varios de ellos sostienen, aún participan. Pensamos que este punto de partida comprobará mucho de lo arriba apuntado, puesto que la historia es de todos, y todos tenemos derecho, y hasta obligación, de juzgarla y contribuir a su rescate.

La idea de que las masas son las hacedoras de la historia orienta, de manera espontánea, estos fragmentos:

La revolución a la que yo me incorporé la podría detínir como el estallido inevitable del pueblo, que a semejanza de una caldera que está haciendo vapor, estalla; ya no puede soportar más (...) Para mí fue una cosa inevitable, y el pueblo en sí - tengo la certeza-, inclusive los ideólogos de la revolución, los Flores Magón, precursores de la revolución, sí tenían un concepto claro. Le puedo decir que la gran mayoría de los que fuimos a la Revolución no fuimos sino a consecuentar con el sentir general del pueblo (...) sacudirse ese estado de cosas que no se podía soportar más. ${ }^{10}$ Yo empecé a entrar en la lucha revolucionaria primeramente en la parte social, en la parte de convencimiento hacia las masas, ya que las masas, por los años que habian tenido que vivir bajo la opresión, no tenían voluntad propia. Eran masas que las movía el capataz, eran masas que las movía el amo, y que no sabian a dónde iban. Entonces empezamos a despertar en las masas el espíritu de ciudadania, el espiritu de hombría para que reclamaran a lo que tenían derecho. ${ }^{11}$

- La trascendencia que cada individuo tiene para la historia queda reflejada en las siguientes líneas:

Ojalá y que pueda servir mi humilde participación. Pues yo realmente no figuré en la Revolución en forma destacada. Contribuí con mi grano de arena, en forma humilde. ${ }^{12}$

Con sus palabras, otro personaje nos señala la importancia de todos los que se sumaron al movimiento:

9 Bertrand Russell, Ensayos filosóficos, Alianza Editorial, Madrid, 1968, p. 92.

${ }^{10}$ Entrevista al teniente coronel Eduardo Angeles Meraz, realizada por Alicia Olivera de Bonfil y América Teresa Briseño, el día 8 de diciembre de 1972, en la ciudad de México. Archivo de la Palabra del Instituto de Investigaciones Dr. José María Luis Mora, México. $\mathrm{PHO} / 1 / 31$, p. 51 .

${ }^{1}$ Entrevista al teniente coronel Arturo Pérez Flores, realizada por Jaime Alexis Arroyo, el 13 de enero de 1961. Archivo de la Palabra del Instituto de Investigaciones Dr. José María Luis Mora, México. PHO/1/3, p. 2-3.

12 Entrevista al capitán primero Jorge Ceceña Quiroz, realizada por María Isabel Souza, el día 12 de julio de 1973, en la ciudad de México. Archivo de la Palabra del Instituto de Investigaciones Dr. José Maria Luis Mora, México. PHO/1/6, p. 36. 
Así es que ustedes que se dedican a formular la historia; pues deben ustedes siempre de incorporar, en la historia, a todos los soldados que perdieron la vida, porque como luego me ha tocado a mi hablar, pos que ái los compañeros: "¡Pos que hable el compañero y que hable!" Bueno, pues yo conceptủo. Y desde luego les digo que yo no tengo palabras floridas, pero lo que voy a decirles, todito eso, son momentos vividos. ${ }^{13}$

Mediante testimonios, también es posible captar la esencia de los ideales populares que llevaron a la lucha:

Ingresé a la Revolución porque tenía deseos de que cambiara la situación del pais, que no hubiera tanto bandido, tanto sinvergüenza que acaparaba el dinero para ellos y la gente pobre muriéndose de hambre (...) yo pensaba que teníamos que pelear contra esa gente que se apoderaba del dinero y que la gente pobre tuviera suficiente dinero para vivir como la gente. ${ }^{14}$

$\mathrm{El}$ rescate de diferentes visiones acerca de la historia permite conocer de una manera más imparcial puntos de vista sobre sectores que han quedado marginados:

- Sinceramente le voy a decir mi opinión. Ha logrado un poco, una cantidad a los más abusados de los pueblos, que entraron a esa revolución y que luego se convirtieron en líderes muchos de ellos; pero el verdadero indigena, el verdadero indio de las diferentes regiones del país, está tan aplastado como en la época de Don Porfirio, y siguen igual. Hay hambre, miseria; porque yo lo veo, todavia andan con sus trajes primitivos y esos hombres no fueron a la revolución, para ellos no hubo revolución, ni saben quién gobierna México. (...) Lo que le digo lo digo y me sale del corazón. Y en un paredón puedo jurarle a usted que si me invitaran a ir a otro movimiento armado para lograr lo que logramos con esto que acaba de pasar, no voy, mejor me quedo en mi casa. ${ }^{15}$

La relación entre el pasado y el presente es un conocimiento que se nutre de la experiencia de quienes han presenciado los hechos históricos:

No, la Revolución mexicana no ha terminado, ni terminará; es interminable, tienen que ir mirando según como vienen los adelantos y todo eso, pues la Revolución también tiene que ir adelantando y pues haciendo más y más, y ver por ejemplo la época en que estamos, cómo tienen que ir adelantando forzozamente, porque ven una cosa que no está bien y tienen que irla reformando y reformando. ${ }^{16}$

13 Entrevista al mayor médico cirujano José Raya Rivera, realizada por María Isabel Souza, el día 20 de julio de 1973, en Parral, Chihuahua. Archivo de la Palabra del Instituto de Investigaciones Dr. José María Luis Mora, México. PHO/1/69, p. 37.

14 Entrevista al señor Paulino Fontes, realizada por Jaime Alexis Arroyo, febrero de 1961, en la ciudad de México. Archivo de la Palabra del Instituto de Investigaciones Dr: José María Luis Mora, México. PHO/1/12, p. 19.

is Entrevista al coronel José Acevedo Basso, realizada por Jaime Alexis Arroyo, febrero de 1961, en la ciudad de México. Archivo de la Palabra del Instituto de Investigaciones Dr. José Maria Luis Mora, México. PHO/1/5, p. 23.

${ }_{16}$ Entrevista al señor coronel Jesús Heredia Chacón, realizada por Maria Isabel Souza, el día 19 de julio de 1973, en la ciudad de México. Archivo de la Palabra del Instituto de Investigaciones Dr. José María Luis Mora, México. PHO/1/68, p. 18-19. 
Nuestros gobernantes constantemente están diciendo al pueblo que el gobierno emana de la Revolución, que es un gobierno revolucionario; esperaremos a que de verdad cumplan y acaben con tanta lacra que aún existe; hay que tomar mucho en cuenta que los postulados de la Revolución son divinos, que no se olviden el porqué de tantos sacrificios que se hicieron en aquellos inolvidables y sangrientos combates de Bachimba, Ciudad Juárez, Tierra Blanca, Chihuahua, Torreón (...) y muchísimos más donde se combatió con furia y en donde siempre triunfó la Revolución. Ahora a nuestro supremo gobierno le toca cumplir y seguir adelante. ${ }^{17}$

La Revolución no se inició por nada, el sufrimiento de nosotros fue grandísimo cuando nosotros tiramos de aquellos tiempos de Porfirio Díaz. (...) Hoy usted es libre para pensar, libre para amar, libre para querer ir a trabajar. El gobierno de Porfirio Díaz fue grande y muy hermoso, nos dio harto de tragar, pero si nos dio una esclavitud muy triste para ser pobres en la vida misma. Así es la verdad de los seres humanos. Usted es juventud de la existencia de la vida, es la juventud chula de la actualidad de nuestro mundo. Nosotros, los viejos que estamos perdidos, estamos humillados, pero les dimos una libertad tan linda y tan hermosa, que no tienen más que pensar, ser y vivir sobre su mismo mundo. ${ }^{18}$

La revolución se inicia el 20 de noviembre de 1910. Ese es el inicio de la Revolución y, hasta la fecha, creo que no ha terminado; yo soy de los que me indigno cuando dicen que la Revolución está terminada, que esto es otra cosa, que es una cosa del Che Guevara, de esto, de lo otro; son absurdos ésos. La revolución no ha terminado. Todavía las ideas del porfirismo, las ideas de la reacción están vivas y por debajo del agua trabajan todo lo que más pueden, para echar abajo todo lo que es de origen revolucionario. ${ }^{19}$

Presentamos algunos juicios emitidos en relación con la producción historiográfica, sus fallas y sus aciertos:

La gente ahora habla y dice y torna iverdad?, pero habla de acuerdo con lo que se les viene a la cabeza, no como los que lo vimos. ${ }^{20}$

¡A h! Muchos libros están acercados a la verdad (...) Hay muchos libros de la Revolución en que cada quien habla según le cuentan, pero los hechos fallan mucho. ${ }^{21}$

Mire usted, hasta entre mis amigos a quienes yo quiero mucho y respeto, encuentro mucha pasión, yo por eso he esperado mucho el tiempo para hablar y para escribir (y creo que ya no voy a escribir) porque no me parece que un historiador deje de tener pasión, puesto

17 Entrevista al doctor Francisco Ruiz Moreno, realizada por María Isabel Souza, el I7 de julio de 19\%3, en Ciudad Juárez, Chihuahua. Archivo de la Palabra del Instituto de Investigaciones Dr. José María Luis Mora, México. PHO/1/66, p. 25.

18 Entrevista al señor José López, realizada por Jaime Alexis Arroyo, el 11 de enero de 1961, Archivo de la Palabra del Instituto de Investigaciones Dr. José María Luis Mora, México. PHO/1/2, p. 15.

19 Entrevista al Ingeniero Juan Hurtado y Olin, realizada por Eugenia Meyer, el 14 de diciembre de 1972, en la ciudad de México. Archivo de la Palabra del Instituto de Investigaciones Dr. José María Luis Mora, México. PHO/1/30, p. 18.

${ }^{20}$ Entrevista al capitán primero Leonardo J. Mendizábal, realizada por Jaime Alexis Arroyo, el 18 de enero de 1961. Archivo de la Palabra del Instituto de Investigaciones Dr. José Maria Luis Mora, México. PHO/1/4, p. 7.

${ }^{21}$ Entrevista al coronel Jesús Arias Villaseñor, realizada por América Teresa Briseño y Maria Isabel Souza, el I de marzo de 1973, en la ciudad de México. Archivo de la Palabra del Instituto de Investigaciones Dr. José Maria Luis Mora, México. PHO/1/44,p. 63. 
que todo mundo la siente para hallar la justicia, la verdad, buscar la razón; pero no con egoísmo, porque entonces ya se echa a perder todo lo principal, que es la investigación de la verdad. ${ }^{22}$

En mi concepto, la historia de México se ha escrito bien salvo ciertos apasionamientos que tiene todo historiador, iporque es humano! y el humano naturalmente está sujeto a ciertas procedencias y aunque naturalmente los hechos sean palpables y tenga que decirlos; pero ya los dice en una forma menos convincente, menos real y menos veraz. Ahora que ya pasó la pugna de las facciones propiamente, se debería llamar "una familia revolucionaria" porque todos fuimos revolucionarios cada quien con nuestro... pues pudiera decirse propiamente con nuestras jefaturas. ${ }^{23}$

La historia, al igual que las otras ciencias sociales, debe conducir a corto o mediano plazo a encaminar la práctica concreta. Este principio es ińterpretado a su manera, por otro de los entrevistados:

(Mensaje a la juventud) Sigan leyendo la cuestión de la revolución. Los puntos más interesantes son el principio y la Revolución, precisamente; sobre todo la comprensión que debe repartirse al pueblo para que se vaya cada día preparando mejor, cada uno en lo personal y su grupo, la cuestión masiva, todo que sea agradable, es lo que espera uno esa cosa. Y que se fijen todos en el campo, ojalá que hubiera muchachos, jóvenes decentes que se dedicaran al campo; no nomás de teoría, sino de práctica, para que sepan repartir y compartir la ayuda. La enseñanza es una gran cosa así, hay zonas muy abandonadas, muy tristes de nuestro país así, sobre todo lo del campo, de lo demás ahí más o menos se va yendo. ${ }^{24}$

Sin duda, cada historiador decidirá cuáles serán las fuentes de las que se nutra su análisis. Si elige considerar también esas otras visiones para construir la historia, tal vez le sirva el siguiente consejo:

A los historiadores les deseo el mejor de los éxitos, que averigüen siempre la verdad, caiga quien caiga. ${ }^{25}$

La reconstrucción y la difusión de nuestra historia requiere una gran dosis de interés por lo humano; detrás de cada proceso histórico se encuentran miles -o hasta millones - de acciones, experiencias, anhelos, frustraciones y conquistas de hombres y mujeres que jamás verán su nombre registrado en una enciclopedia, pero sin cuyos granos de arena no seriamos lo que somos. Desgraciadamente, pretender darles voz a todos ellos para cuanto tengan que decir no es más que una bella utopía; sin embargo, cualquier esfuerzo que se emprenda en ese sentido, si bien no es más que una pequeñísima parte de la labor arriba apuntada, se sumará a otros similares. Asi, poco a poco, iremos construyendo nuestra historia popular.

22 Entrevista al señor Enrique M. Zepeda, realizada por Eugenia Meyer, los días 24 de marzo. 3 de abril, $1 /$ de mavo de 1973, en la ciudad de México. Archivo de la Palabra del Instituto de Investigaciones Dr. José Maria Luis Mora, México. PHO/1/47, p. 175.

23. Entrevista al señor Leonardo Banuet, realizada por América Teresa Briseño, el día 12 de junio de 1973, en la ciudad de México. Archivo de la Palabra del Instituto de Investigaciones Dr. José María Luis Mora, México. PHO/1/46, p. 74.

${ }_{25}$ Entrevista al capitán Cândido Avilés, realizada por América Teresa Briseño y María Isabel Souza, el 31 de enero de 1973, en la ciudad de México. Archivo de la Palabra del Instituto de Investigaciones Dr. José María Luis Mora, México. PHO/1/40, p. 34. 